Supporting information

\title{
Spin Transition Resulting from the Generation of a New Polymorph in the Metastable Phase
}

Svyatoslav Tolstikov, ${ }^{\mathrm{a}, \mathrm{c}, *}$ Irina Golomolzina, ${ }^{\mathrm{a}}$ Sergey V. Fokin, ${ }^{\mathrm{a}}$ Artem Bogomyakov, ${ }^{\mathrm{a}, \mathrm{b}}$ Vitaly Morozov, ${ }^{a, b}$ Sergey Tumanov, ${ }^{a, b}$ Olga Minakova, ${ }^{a, b}$ Sergey Veber, ${ }^{a, b}$ Matvey V. Fedin, ${ }^{\text {a,b }}$ Sergey A. Gromilov, ${ }^{\mathrm{d}}$ Galina V. Romanenko, ${ }^{\mathrm{a}}$ Victor Ovcharenko, ${ }^{\mathrm{a}, \mathrm{c}}$

anternational Tomography Center, SB RAS, 630090 Novosibirsk, Russia

bNovosibirsk State University, 630090 Novosibirsk, Russia

'Zelinsky Institute of Organic Chemistry, RAS, 119991 Moscow, Russia

dNikolaev Institute of Inorganic Chemistry, SB RAS, 63090 Novosibirsk, Russia

\section{Contents:}

Absorption band integration procedure in variable-temperature mid-FTIR measurements ..S2

EPR spectra of $\left[\mathrm{Cu}(\mathrm{hfac})_{2} \mathrm{~L}^{5 \mathrm{Et}}\right]$ in the $300 \rightarrow 50 \rightarrow 300 \mathrm{~K}$ temperature cycle S4

Crystal data and details of experiments S5

Comparison of the unit cells and chains of two polymorphs S6

Comparison of powder patterns for $\alpha-$ and $\beta-\left[\mathrm{Cu}(\mathrm{hfac})_{2} \mathrm{~L}^{5 \mathrm{Et}}\right]$ calculated from single crystal XRD data. Experimental diffraction pattern S8

Theoretical fitting 


\section{Absorption band integration procedure in variable-temperature mid-FTIR measurements}

In order to distinguish two closely located characteristic absorption bands of $\left[\mathrm{Cu}(\mathrm{hfac})_{2} \mathrm{~L}^{5 \mathrm{Et}}\right]$, we used the following integration procedure.

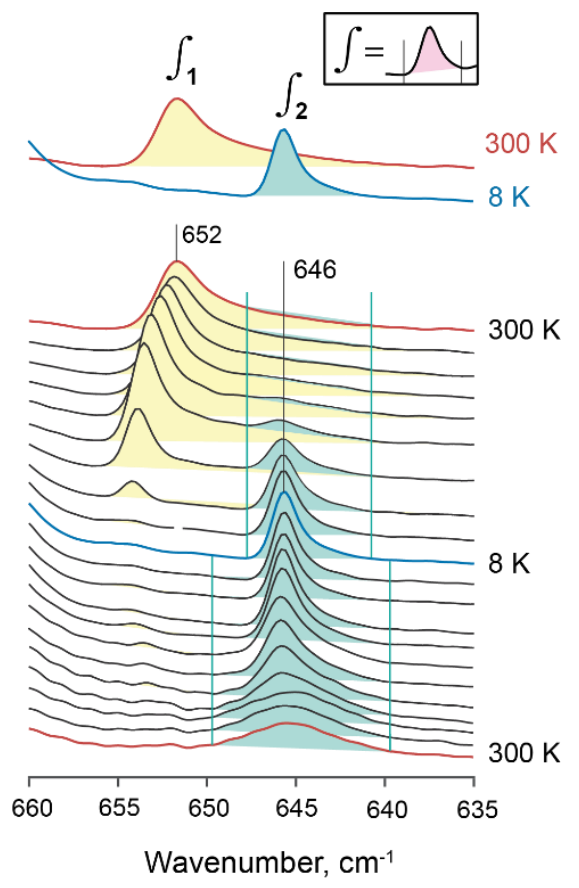

Figure S1. Representation of integration procedure of the characteristic absorption bands of $\left[\mathrm{Cu}(\mathrm{hfac})_{2} \mathrm{~L}^{5 \mathrm{Et}}\right]$ in variable-temperature mid-FTIR experiments.

For the absorption band $652 \mathrm{~cm}^{-1}$ corresponding to the $\alpha-\left[\mathrm{Cu}(\mathrm{hfac})_{2} \mathrm{~L}^{5 \mathrm{Et}}\right]$ polymorph, the integrated intensity was calculated as follows. Both bands were integrated in the range $656-636 \mathrm{~cm}^{-1}$ with subsequent subtraction of the $646 \mathrm{~cm}^{-1}$ band integrated in the range 650 $636 \mathrm{~cm}^{-1}$.

For the absorption band $646 \mathrm{~cm}^{-1}$ corresponding to the $\beta$ - $\left[\mathrm{Cu}(\mathrm{hfac})_{2} \mathrm{~L}^{5 \mathrm{Et}}\right]$ polymorph, we performed integration in two ranges for the following reason. The first cooling is accompanied by the $\alpha \rightarrow \beta$ transition, so the adjacent absorption band $652 \mathrm{~cm}^{-1}$ may contribute to the integral. To exclude the influence of the adjacent band, the absorption band $646 \mathrm{~cm}^{-1}$ was integrated in the range $647.9-640.8 \mathrm{~cm}^{-1}$ during the first cooling. After the first cooling, the $652 \mathrm{~cm}^{-1}$ band irreversibly vanished, and the remaining integrals were calculated in the range $649.5-639.4 \mathrm{~cm}^{-1}$.

All integrals were calculated using the integration approach shown as highlighted areas in Figure S1. 


\section{EPR spectra of $\left[\mathrm{Cu}(\mathrm{hfac})_{2} \mathrm{~L}^{5 \mathrm{Et}}\right]$ in the $300 \rightarrow 50 \rightarrow 300 \mathrm{~K}$ temperature cycle}

a)

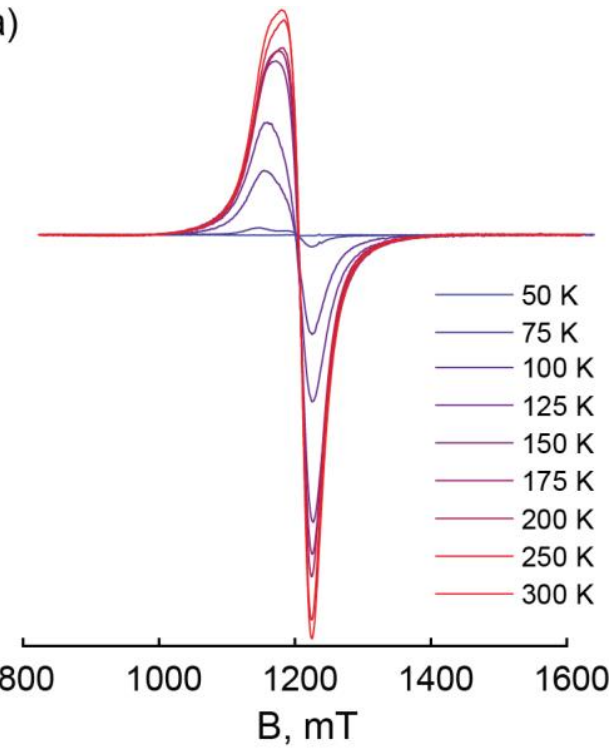

b)

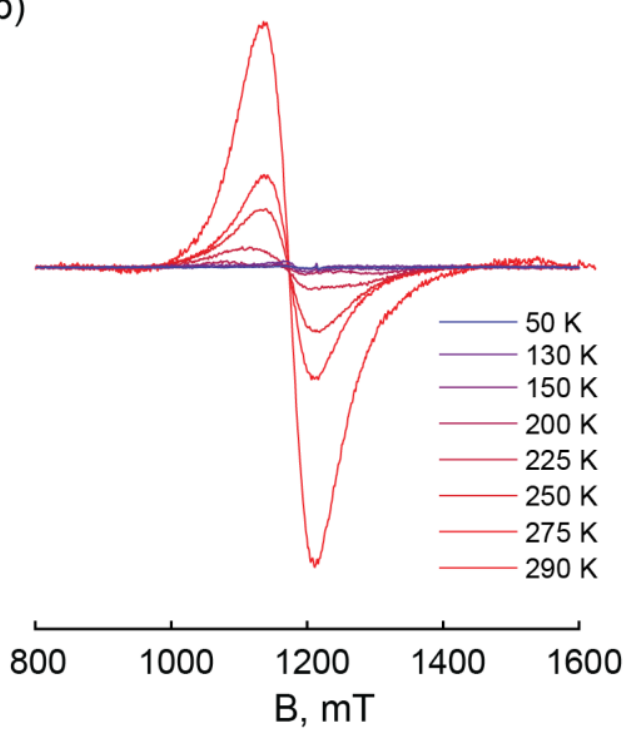

Figure S2. Temperature-induced changes in the EPR spectra of $\left[\mathrm{Cu}(\mathrm{hfac})_{2} \mathrm{~L}^{5 \mathrm{Et}}\right]$ under cooling (a) and subsequent heating (b) of the sample. The amplitudes were normalized to the Boltzmann factor of the spin system.

Figure S2 shows the temperature-induced changes in the EPR spectra of $\left[\mathrm{Cu}(\mathrm{hfac})_{2} \mathrm{~L}^{5 \mathrm{Et}}\right]$ in the $300 \rightarrow 50 \rightarrow 300 \mathrm{~K}$ temperature cycle, where the spectra were normalized to the Boltzmann factor of the spin system. These spectra were used to calculate the temperature dependence of the double integral of the EPR signal. The resulting dependence should roughly correlate with the temperature dependence of the effective magnetic moment of the system assuming that (a) the whole EPR spectra is detected and integrated and (b) the sensitivity of the EPR spectrometer is constant over the whole temperature range.

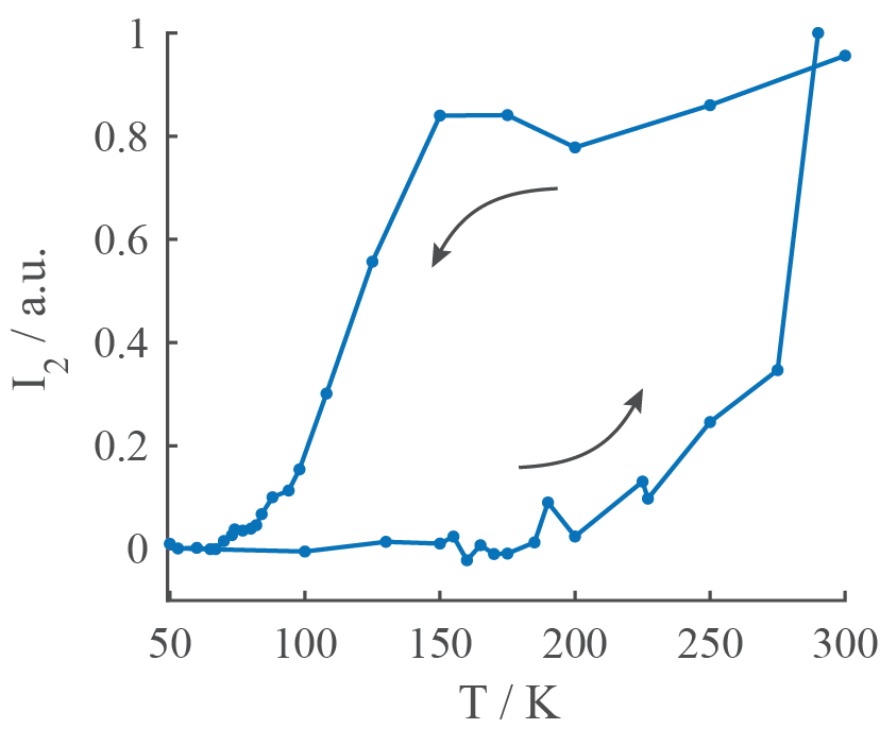

Figure S3. Temperature dependence of the double-integral of the EPR spectra of $\left[\mathrm{Cu}(\mathrm{hfac})_{2} \mathrm{~L}^{5 \mathrm{Et}}\right]$ measured in the $300 \rightarrow 50 \rightarrow 300 \mathrm{~K}$ temperature cycle. 
Although the sensitivity of the EPR spectrometer is not a temperature-independent parameter, the described approach gives reasonable correlation with the magnetic data obtained using SQUID magnetometry. Figure S3 shows the changes in the second integral of the spectra shown in Figure S2. After cooling, the spectrum intensity gradually decreases starting from $150 \mathrm{~K}$ and completely disappears between 50 and $75 \mathrm{~K}$. After heating, the signal starts to appear at $200 \mathrm{~K}$ and closes the hysteresis loop at $300 \mathrm{~K}$. 
Table S1. Crystal data and details of experiments

\begin{tabular}{|c|c|c|c|c|c|c|}
\hline Compound & \multicolumn{6}{|c|}{$\mathrm{C}_{22} \mathrm{H}_{21} \mathrm{CuF}_{12} \mathrm{~N}_{4} \mathrm{O}_{6}$} \\
\hline Formula & \multicolumn{4}{|c|}{$\alpha-\left[\mathrm{Cu}(\mathrm{hfac})_{2} \mathrm{~L}^{5 \mathrm{Et}}\right]$} & \multicolumn{2}{|c|}{$\beta-\left[\mathrm{Cu}(\mathrm{hfac})_{2} \mathrm{~L}^{5 \mathrm{Et}}\right]$} \\
\hline FW & \multicolumn{6}{|c|}{728.97} \\
\hline $\mathrm{T}, \mathrm{K}$ & 296 & 200 & 150 & 100 & 296 & 100 \\
\hline Space group, $Z$ & \multicolumn{6}{|c|}{$P 21 / n, 4$} \\
\hline $\begin{array}{l}a, \\
b, \\
c, \AA\end{array}$ & $\begin{array}{c}11.3558(18) \\
21.392(3) \\
12.982(2) \\
\end{array}$ & $\begin{array}{c}11.1871(12) \\
21.273(3) \\
12.8790(14) \\
\end{array}$ & $\begin{array}{c}11.2321(8) \\
21.2338(14) \\
12.7062(9) \\
\end{array}$ & $\begin{array}{c}11.2704(18) \\
21.111(3) \\
12.591(2) \\
\end{array}$ & $\begin{array}{c}12.6308(14) \\
22.023(3) \\
11.8510(14) \\
\end{array}$ & $\begin{array}{c}12.3941(11) \\
21.863(2) \\
11.1246(11) \\
\end{array}$ \\
\hline$\beta, \circ$ & $108.759(9)$ & $107.901(6)$ & $108.047(4)$ & $108.255(9)$ & $112.775(8)$ & $111.052(4)$ \\
\hline$V, \AA^{3}$ & $2986.0(8)$ & $2916.6(6)$ & $2881.3(4)$ & $2844.8(8)$ & $3039.5(7)$ & $2813.3(5)$ \\
\hline$D_{\mathrm{c}}, \mathrm{g} \mathrm{cm}^{-3}$ & 1.622 & 1.660 & 1.680 & 1.702 & 1.593 & 1.721 \\
\hline$\theta_{\max }$, deg. & 67.627 & 67.652 & 67.747 & 44.951 & 28.315 & 67.255 \\
\hline $\begin{array}{l}\text { Ihkl (meas/uniq) } \\
R_{\text {int }}\end{array}$ & $\begin{array}{c}21418 / 5307 \\
0.0455 \\
\end{array}$ & $\begin{array}{c}17333 / 5079 \\
0.1084 \\
\end{array}$ & $\begin{array}{c}26129 / 48467 \\
0.0697 \\
\end{array}$ & $\begin{array}{c}4750 / 1846 \\
0.0795 \\
\end{array}$ & $\begin{array}{c}18752 / 5252 \\
0.0781 \\
\end{array}$ & $\begin{array}{c}17382 / 4931 \\
0.0475 \\
\end{array}$ \\
\hline$I_{\mathrm{hkl}}(I>2 \sigma I) / \mathrm{N}$ & $3613 / 505$ & $2388 / 460$ & $3732 / 434$ & $1112 / 406$ & $27067 / 408$ & $4295 / 406$ \\
\hline GooF & 1.002 & 0.822 & 1.092 & 1.023 & 1.022 & 0.829 \\
\hline$R_{1} / w R_{2} \quad\left(I>2 \sigma_{I}\right)$ & $0.0427 / 0.1112$ & $0.0523 / 0.1123$ & $0.0709 / 0.1935$ & $0.0587 / 0.1283$ & $0.0913 / 0.1494$ & $0.0585 / 0.1622$ \\
\hline$R_{1} / w R_{2} \quad$ (all data) & $0.0672 / 0.1285$ & $0.1199 / 0.1337$ & $0.0902 / 0.2052$ & $0.1159 / 0.1520$ & $0.3111 / 0.2563$ & $0.0660 / 0.1719$ \\
\hline $\mathrm{CCDC}$ & 2005023 & 2032444 & 2032443 & 2005022 & 2005025 & 2005024 \\
\hline
\end{tabular}




\section{Comparison of the unit cells and chains of two polymorphs}
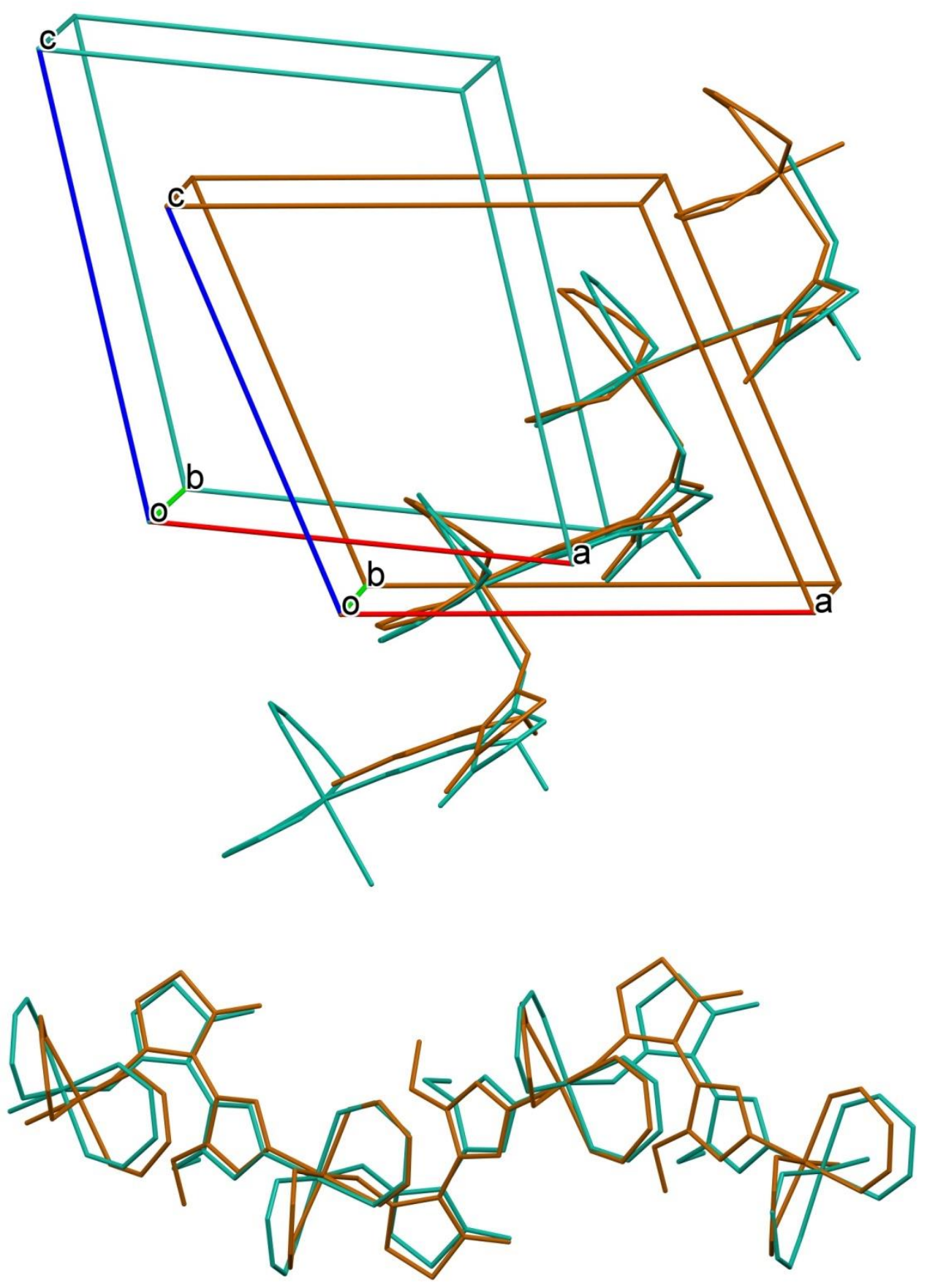

Figure S4. Comparison of the unit cells and chains of two polymorphs at $295 \mathrm{~K}$ : $\alpha-\left[\mathrm{Cu}(\mathrm{hfac})_{2} \mathrm{~L}^{5 \mathrm{Et}}\right]$ (bluish green) and $\beta-\left[\mathrm{Cu}(\mathrm{hfac})_{2} \mathrm{~L}^{5 \mathrm{Et}}\right]$ (brown).

The Figure shows slight differences between the chain structure in both polymorphs. At the same time, it shows that the transformation of one unit cell to the other is rather complex. 


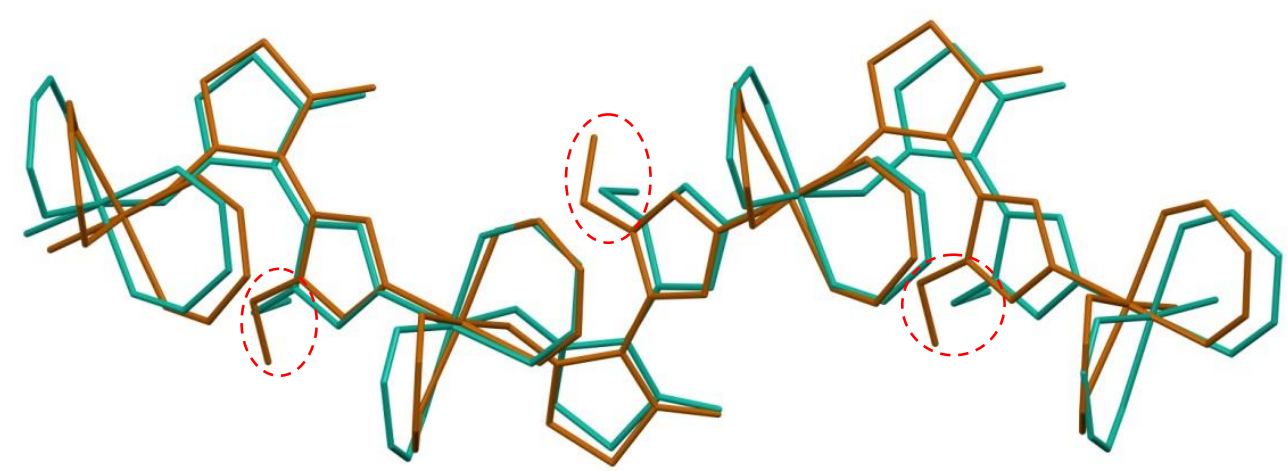

Figure S5. Superposition of the chains from $\alpha-\left[\mathrm{Cu}(\mathrm{hfac})_{2} \mathrm{~L}^{5 \mathrm{Et}}\right]$ (bluish green) and $\beta$ - $\left[\mathrm{Cu}(\mathrm{hfac})_{2} \mathrm{~L}^{5 \mathrm{Et}}\right]$ (brown). The ethyl groups from different chains are marked by red dash ellipses.

Figure S5 shows that the motifs of the polymer chains in both modifications are similar. The main difference in their structure is associated with the orientation of the ethyl groups (highlighted by red dash ellipses). 


\section{Comparison of powder patterns for $\alpha-$ and $\beta-\left[\mathrm{Cu}(\mathrm{hfac})_{2} \mathrm{~L}^{5 \mathrm{Et}}\right]$ calculated from single crystal XRD data. Experimental diffraction pattern}
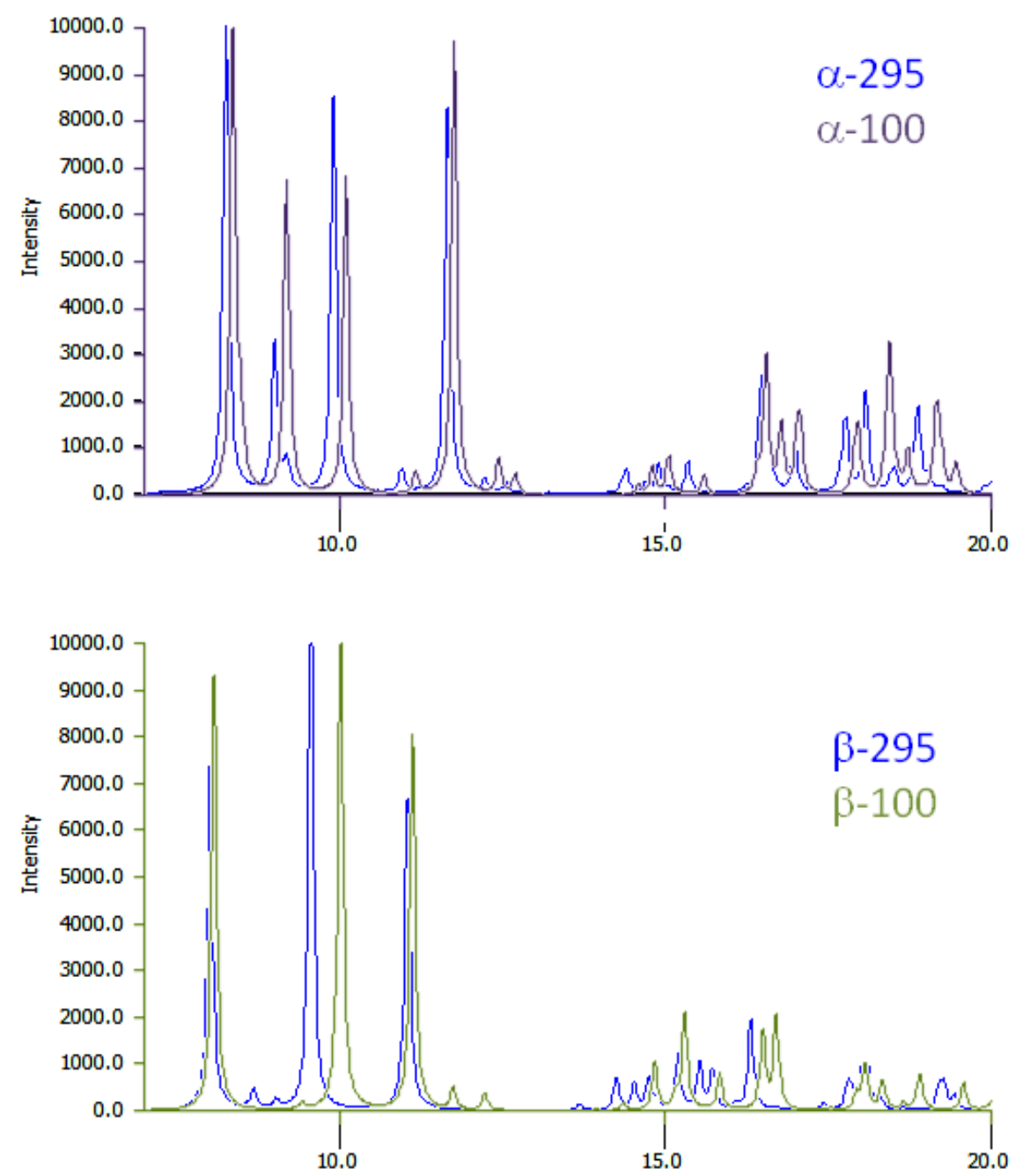

Figure S6. Powder XRD data for $\alpha-(295$ and $100 \mathrm{~K})$ and $\beta-\left[\mathrm{Cu}(\mathrm{hfac})_{2} \mathrm{~L}^{5 \mathrm{Et}}\right](295$ and $100 \mathrm{~K})$ calculated using single crystal XRD data.

Diffraction patterns of $\alpha-$ and $\beta-\left[\mathrm{Cu}(\mathrm{hfac})_{2} \mathrm{~L}^{5 \mathrm{E} t}\right]$ powders, calculated from the data obtained for single crystals, noticeably change with temperature and differ for each of their phases (Figure S6).

In an effort to see the accumulation of the $\beta$-phase upon cooling, we performed additional experiments with the $\alpha-\left[\mathrm{Cu}(\mathrm{hfac})_{2} \mathrm{~L}^{5 \mathrm{Et}}\right]$ single crystal in the range $295-100 \mathrm{~K}$. At 200 and $150 \mathrm{~K}$, we were able to obtain satisfactory data, but they did not reveal the presence of the $\beta$-phase in noticeable amounts, as evidenced by insignificant changes in the $\mathrm{Cu}-\mathrm{O}_{\mathrm{NO}}$ distances (Table 2). Slow cooling of the crystal below $150 \mathrm{~K}$ led to its cracking, which is associated with the transformation of the $\alpha$-phase into the $\beta$-phase. However, by comparing the diffraction patterns of $\alpha$ - and $\beta-\left[\mathrm{Cu}(\mathrm{hfac})_{2} \mathrm{~L}^{5 \mathrm{Et}}\right]$ powders calculated from the single crystal data, we can choose a peak sensitive to temperature changes (in Figure S7, this area is 
highlighted by a red rectangle). After the transition from $\alpha$ - to $\beta$-phase at $100 \mathrm{~K}$, this peak clearly demonstrates a shift toward large angles and a significant change in intensity.

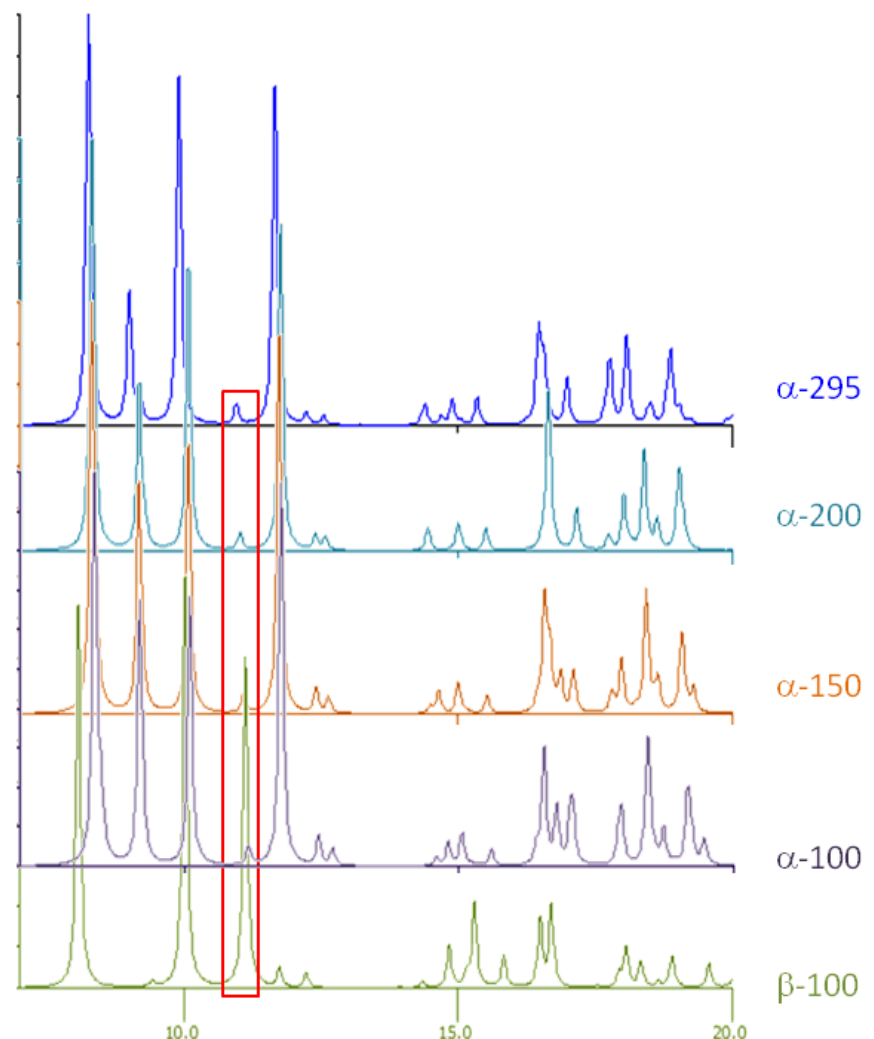

Figure S7. Powder XRD data for $\alpha-\left[\mathrm{Cu}(\mathrm{hfac})_{2} \mathrm{~L}^{5 \mathrm{Et}}\right]$ (at 295, 200, 150, and $100 \mathrm{~K}$ ) and $\beta$ $\left[\mathrm{Cu}(\mathrm{hfac})_{2} \mathrm{~L}^{5 \mathrm{Et}}\right]$ (at $100 \mathrm{~K}$ ) calculated using single crystal XRD data.

In Figure 8S, the experimental diffraction patterns at 298, 250, 200, 150, 125, and 100 $\mathrm{K}$ are shown by a gray line. For comparison, the magenta line represents the diffractogram calculated from the single crystal data for $\alpha-\left[\mathrm{Cu}(\mathrm{hfac})_{2} \mathrm{~L}^{5 \mathrm{Et}}\right]$. For comparison, the brown pattern at the bottom represents the diffractogram calculated from the single crystal data for $\beta$ - $\left[\mathrm{Cu}(\mathrm{hfac})_{2} \mathrm{~L}^{5 \mathrm{Et}}\right]$. The $\mathrm{X}$-ray diffraction analysis showed that at $298 \mathrm{~K}$ the experimental diffractogram of $\alpha$ - $\left[\mathrm{Cu}(\mathrm{hfac})_{2} \mathrm{~L}^{5 \mathrm{Et}}\right]$ was in good agreement with the single crystal data. Several low-intensity reflections correspond to the $\beta$ - $\left[\mathrm{Cu}(\mathrm{hfac})_{2} \mathrm{~L}^{5 \mathrm{Et}}\right]$ phase in position. When the temperature decreased to $125 \mathrm{~K}$, there were no noticeable changes (except for the small shifts associated with a decrease in the unit cell parameters). The light brown stripe and the red arrow in Fig. 8S highlight the appearance of the $\beta$-phase upon cooling to $100 \mathrm{~K}$. 


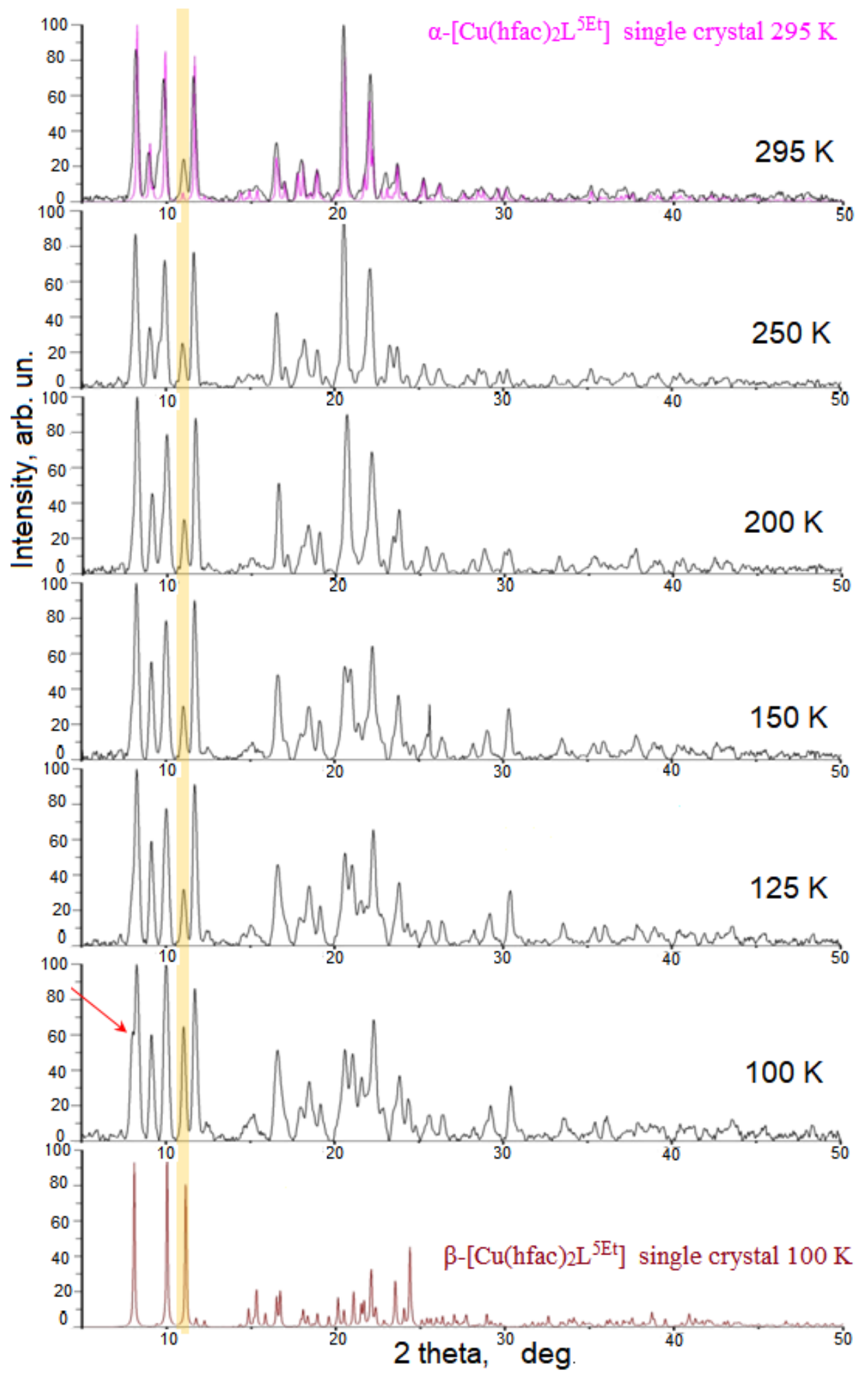

Figure S8. Change in the diffraction pattern of $\alpha-\left[\mathrm{Cu}(\mathrm{hfac})_{2} \mathrm{~L}^{5 \mathrm{Et}}\right]$ with decreasing temperature. 


\section{Theoretical fitting}

Based on the concept of gradual transition of exchange clusters inside the $\beta$ modification from low-temperature (LT) to high-temperature (HT) state at increased temperatures, we can evaluate the exchange integrals in these states. The $\mu_{\text {eff }}(\mathrm{T})$ dependence can be expressed as a weighted sum of contributions from the LT and HT states: $\mu$ eff $(T)=$ $\mathrm{w}(T) \cdot \mu_{\mathrm{eff}}^{(\mathrm{LT})}(T)+(1-\mathrm{w}(T)) \cdot \mu_{\mathrm{eff}}{ }^{(\mathrm{HT})}(T)$, where $0<\mathrm{w}(T)<1$. As the intercluster and interchain exchange interactions are small, the theoretical calculation of $\mu_{\text {eff }}(\mathrm{T})$ can be performed on the basis of the simple two-spin Hamiltonian $H=-2 J \mathrm{~S}_{\mathrm{NO}} \cdot \mathrm{S}_{\mathrm{Cu}}$. In this case, the experimental curve $\mu_{\text {eff }}(\mathrm{T})$ should fit between the theoretical fitting curves corresponding to two possible values of $J_{\mathrm{HT}}$ and $J_{\mathrm{LT}}$. The results that were fitted as described are shown in Figure $S 9$. The red and blue curves in Figure $\mathrm{S} 9$ correspond to $J_{\mathrm{HT}}=-10 \mathrm{~cm}^{-1}$ and $J_{\mathrm{LT}}=-260 \mathrm{~cm}^{-1}$, respectively. It is noteworthy that our DFT( $\omega$ B97m-v/def2-TZVPp) calculation gives close $J$ values: $J(\mathrm{DFT}) \mathrm{HT}$ $=-7.4 \mathrm{~cm}^{-1}$ and $J(\mathrm{DFT})_{\mathrm{LT}}=-287 \mathrm{~cm}^{-1}$.

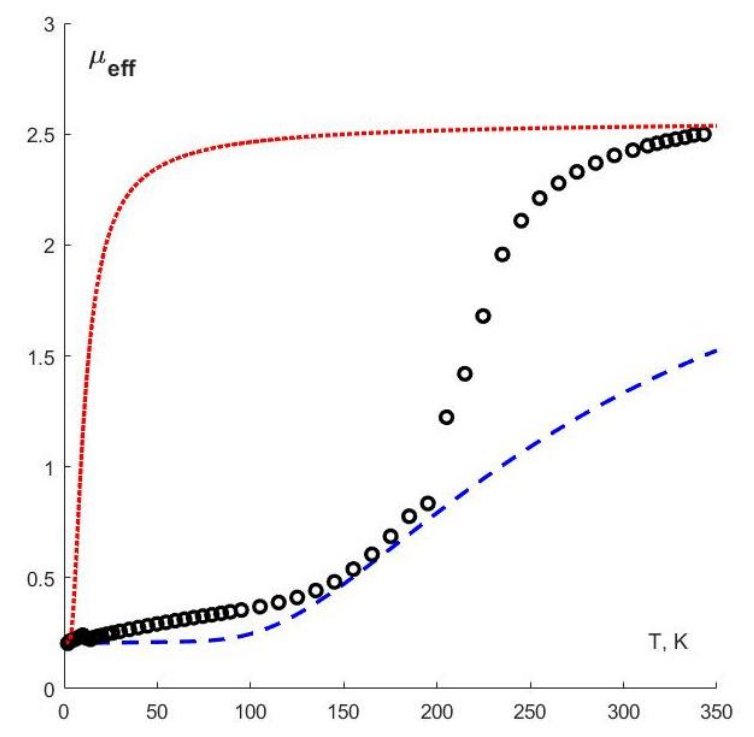

Figure S9. Experimental $\mu_{\text {eff }}(T)$ dependence for $\beta-\left[\mathrm{Cu}(\mathrm{hfac})_{2} \mathrm{~L}^{5 \mathrm{Et}}\right]$ (o) and estimated theoretical curves for $\mu_{\mathrm{eff}}(T)$ in HT limit $\left.\left(J_{\mathrm{HT}}=-10 \mathrm{~cm}^{-1}\right)(----)\right)$ and LT limit $\left(J_{\mathrm{LT}}=-260\right.$ $\left.\mathrm{cm}^{-1}\right)(---)$. The values of $\mathrm{g}$-factors $\mathrm{g}(\mathrm{NO})=2.01$ and $\mathrm{g}\left(\mathrm{Cu}^{2+}\right)=2.16$ were taken from the ESR data. 